\title{
SOME WATER-SOLUBLE POLYMERS AS CORROSION INHIBITORS FOR CARBON STEEL IN ACIDIC MEDIUM
}

\author{
Khalid I. Kabel ${ }^{1}$, L. A. Kamel ${ }^{2}$, R. M. Abou-shahaba ${ }^{2}$, Azza. E. El-Shenawy ${ }^{2}$, Seham Shahen*2 \\ ${ }^{1}$ Petroleum Applications Department, Egyptian Petroleum Research Institute, Naser City, P.O. 11727, Cairo, \\ Egypt. \\ ${ }^{2}$ Department of Chemistry, Faculty of Science, Al-Azhar University, Nasr City, Cairo, Egypt. \\ * Corresponding author. Tel.: 01122739385. E-mail addresses: shahen.seham@yahoo.com
}

\begin{abstract}
Encouraged by the excellent performance of organic polymers as scale inhibitors and anticorrosive coatings, we reasoned that polymers with properly designed structures might also be used as efficient watersoluble corrosion inhibitors. New kind of water soluble hyperbranched polyamide ester (HPAE) synthesized using trimethylol propane as a precursor via Michael addition reaction with diethanolamine. The chemical structure of the prepared polymers was determined by FT-IR. The inhibitive effect of HPAE on the corrosion of steel in $1 \mathrm{M} \mathrm{HCl}$ solution has been investigated using potentiodynamic polarization and electrochemical impedance spectroscopy (EIS) techniques. The results indicated that HPAE inhibited the corrosion of steel and the extent of inhibition increased with HPAE concentrations. Potentiodynamic polarization data suggests mixedmode of corrosion inhibition.
\end{abstract}

Keywords : Polarization, EIS, Electrochemical, Steel, Corrosion, Acid inhibition

\section{INTRODUCTION}

Corrosion is gradual destruction of a material because of its reaction with environment. It is a major industrial problem that has attracted a lot of investigators in recent years $[1,2]$. In the fields of petroleum and oil industry, corrosion represents a huge percentage of the annual economic losses. The most significant corrosion types in petroleum industry are local and general corrosion. Another problem in the operation of pipelines is internal corrosion. The corrosion problems are always associated with the equipment maintenance and operation. This lead to stopping the process partially or even completely, resulting in economic losses ranging between $10 \%$ and $30 \%$ of the whole maintenance budget. Indeed, corrosion control is an essential issue from application point of view and it has been reported that inhibitors are needed to be used which act as a barrier to reduce the aggressiveness of the environments against the corrosion attack [3-5]. Most common type of corrosion inhibitors are organic compounds. Their inhibition property is dependent upon their functional group, which adsorb on the metal surface. Most of the efficient organic compounds acts as inhibitors have oxygen, sulphur, nitrogen atoms and multiple bonds through which they adsorb on metal surface [6-8]. The inhibition efficiency of inhibitors increases in the order of: $\mathrm{O}<\mathrm{N}<\mathrm{S}$ $<\mathrm{P}$ [9-11].

The use of polymers as corrosion inhibitors has attracted considerable attention recently [12]. Polymers are used as corrosion inhibitors because, through their functional groups they form complexes with metal ions and on the metal surface these complexes occupy a large surface area [13,14], thereby blanketing the surface and protecting the metal from corrosive agents present in the solution [15-18]. The inhibitive power of these polymers is related structurally to the cyclic rings, heteroatom (oxygen and nitrogen) that are the major active centers of adsorption [19,20]. Because of the unique characteristics of hyperbranched polymers which have become widely used, they have attracted more attention especially in scientific research and industrial fields such as 
KHALID I. KABEL, et al.

oil industry, corrosion inhibitor, and coating of pipelines [21-23]. The hyperbranched polymers have many advantages, the most significant of which is that it easy to prepare, high solubility in addition low viscosity [24].

In this paper, we have to synthesize a hyperbranched poly amide-ester via Michael addition reaction. These polymers were then investigated for their ability to prevent corrosion of the steel in aggressive aqueous acidic medium.

\section{EXPERIMENTAL}

\subsection{Materials}

\subsubsection{Chemicals}

Diethanolamine (DEA), trimethylol propane (TMP), maleic anhydride(MA), methanol, p-toluene sulfonic acid (p-TSA), N,N-Dimethylacetamide (DMAC), ethyl ether, acetone.

\subsubsection{Solutions}

\section{a-Hydrochloric acid solution}

$1 \mathrm{M} \mathrm{HCl}$ was used as a corrosive solution, and was prepared by diluting concentrated $\mathrm{HCl}$ (37\%) to a required concentration using bidistilled water.

\section{b- Inhibitor solutions}

$100 \mathrm{ml}$ stock solutions of hyperbranched polymers were prepared by dissolving the desired weight of each compound in $100 \mathrm{ml}$ of absolute ethanol, and then the six different concentrations 50, 100, 200, 400, 500 and $1000 \mathrm{ppm}$ were prepared by dilution with known concentration of hydrochloric acid.

\subsubsection{Carbon steel electrode}

Corrosion tests were performed on carbon steel electrode having the following chemical composition (wt.\%): 0.09\% C, $0.09 \% \mathrm{Si}, 0.46 \%$ $\mathrm{Mn}, 0.03 \% \mathrm{P}$ and the remainder Fe.

\subsection{Synthesis techniques}

The synthetic procedure was described in the literature reported by CHEN Q. H. et al [25]

\section{2.1. Synthesis of $\mathbf{A B}_{2}$ monomer}

$\mathrm{AB}_{2}$ monomer was prepared by amidation reaction of DEA and maleic anhydride at a molar ratio of 1/1. $0.1 \mathrm{~mol}$ (9.8060 g) maleic anhydride was dissolved with $20.0 \mathrm{~g}$ DMAC in a three-necked round-bottomed flask at $25^{\circ} \mathrm{C}$ constant temperature. $0.1 \mathrm{~mol}$ (10.5140 g) crystal DEA was heated to be liquid state and poured into the maleic anhydride solution rapidly, and then $10.0 \mathrm{~g}$ more DMAC was added to assure a proper viscosity of mixture for reaction. The reaction mixture was stirred with a magnetic stirrer at $25{ }^{\circ} \mathrm{C}$ for $2 \mathrm{hrs}$ to obtain the DMAC solution of $\mathrm{AB}_{2}$ monomer.

\section{2.2. Synthesis of hydroxyl terminated fourth generation hyperbranched poly amide-ester [4G-( $\mathrm{OH})$ ]}

Hyperbranched poly amide-esters were synthesized through "one-step process" or "pseudo one-step process". TMP was added as a center core. In $100 \mathrm{~mL}$ three-necked roundbottomed flasks, calculated amounts of P- TSA and the obtained $\mathrm{AB}_{2}$ monomer solution were introduced according to various formulae, respectively. A neck mouth of this flask was ventilated a vacuum pump and installed a reflux distillation equipment with water condenser. The flask was put into an oil bath with constant temperature of $120^{\circ} \mathrm{C}$. The mixture was stirred with a magnetic stirrer for 6 hrs under vacuum condition. The crude products were dissolved in 30.0g DMAC, and then precipitated and washed by the mixture solvents of ethyl ether- acetone (vol. ratio is $1 / 1$ ). The process was carried out for several times before the precipitate was dried in vacuo. The synthesized inhibitors were illustrated in Scheme 1, and the chemical structure was confirmed by FT-IR spectroscopic analysis using Nicolet iS10 FT-IRspectrometer, Thermo Fisher Scientific (USA). 
2.3- Method used for Corrosion electrode, saturated calomel electrode (SCE) as Measurements reference electrode and carbon steel as working

\section{Electrochemical techniques}

Electrochemical measurements were performed with a traditional three-electrodes cell using Volta lab 40 (TacusselRadiometerPGZ301) potentiostate and controlled by Tacussel corrosion analysis software model (Voltamaster 4) at under static condition. All experiments were conducted in a electrode.

A- Potentiodynamic polarization curves were obtained by varying the potential automatically from -800 to $-300 \mathrm{mV}$ in relation to a steady-state open circuit potential (EOCP) with the scan rate $2 \mathrm{mV} \mathrm{s}^{-1}$. The polarization curves were obtained after $1 \mathrm{~h}$ in the opencircuit potential.

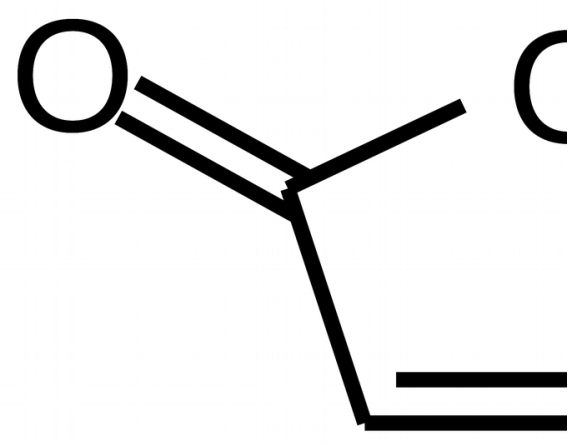

\section{maleic}

Scheme 1 Synthesis of hyperbranched poly amide-ester

conventional three-electrodes glass cell assembly with a platinum wire as auxiliary
B-Electrochemical impedance spectroscopy (EIS) measurements were carried out using a 
potentiostat (VoltaLab PGZ-301) attached to the Zsimpwin software program. The measurements were carried out using AC signal $(10 \mathrm{mV})$ peak to peak at OCP in the frequency range of $100 \mathrm{kHz}-50 \mathrm{mHz}$. In all experiments, the carbon steel electrode was also allowed to reach its stable open- circuit potential (OCP), which occurred after $1 \mathrm{~h}$. EIS diagrams are given in the Nyquist representation.

\subsection{Scanning Electron Microscope (SEM)} Analysis

The surface films were formed on the carbon steel specimens by immersing them in $1 \mathrm{M} \mathrm{HCl}$ solution with and without different concentrations of inhibitors for a period of time of $12 \mathrm{hrs}$.After the immersion period, the specimens were taken out, dried and the nature of the film formed on the surface of the metal specimen was analyzed by SEM techniques to examine the surface morphology. JEOL JSM5500 scanning electron microscope was used for this investigation.

\section{RESULTS AND DISCUSSION}

\subsection{Chemical structure confirmation of the synthesized Inhibitors}

The structural characteristics of the synthesized hyperbranched poly (amide-ester) by FT-IR spectroscopy in the range $4000-500$ $\mathrm{cm}^{-1}$.

\section{$\mathrm{AB}_{2}$ monomer}

Fig. 1 illustrates the FTIR spectra of $\mathrm{AB}_{2}$ monomer. It shows that in the $\mathrm{AB}_{2}$ monomer spectrum, strong absorption of tertiary amine and hydroxyl group stretching vibration occur at about 1614 and $3387 \mathrm{~cm}^{-1}$, respectively. Band at $1714 \mathrm{~cm}^{-1}$ is ascribable to isolated aromatic carboxylic acid carbonyl group [26]. The results show that the reaction between diethanolamine and maleic anhydride is amidation but not esterification under experimental conditions and the prepared $A_{2}$ monomer is an amine compound containing hydroxyl groups. The structure of $\mathrm{AB}_{2}$ monomer is comparable with the theoretic one. And so, the synthesis process is sound.

\section{Structural description for structural description for hyperbranched poly amide- ester generation (G4)}

Fig. 2 reveals the FTIR spectra of hyperbranched poly amide-ester generation 4 (G4), the spectrum of (G4) possesses strong absorption bands at 1726, 1657, 1176 and 1054 $\mathrm{cm}^{-1}$ for tertiary amide-ester group, indicating that the polymerization reaction has been

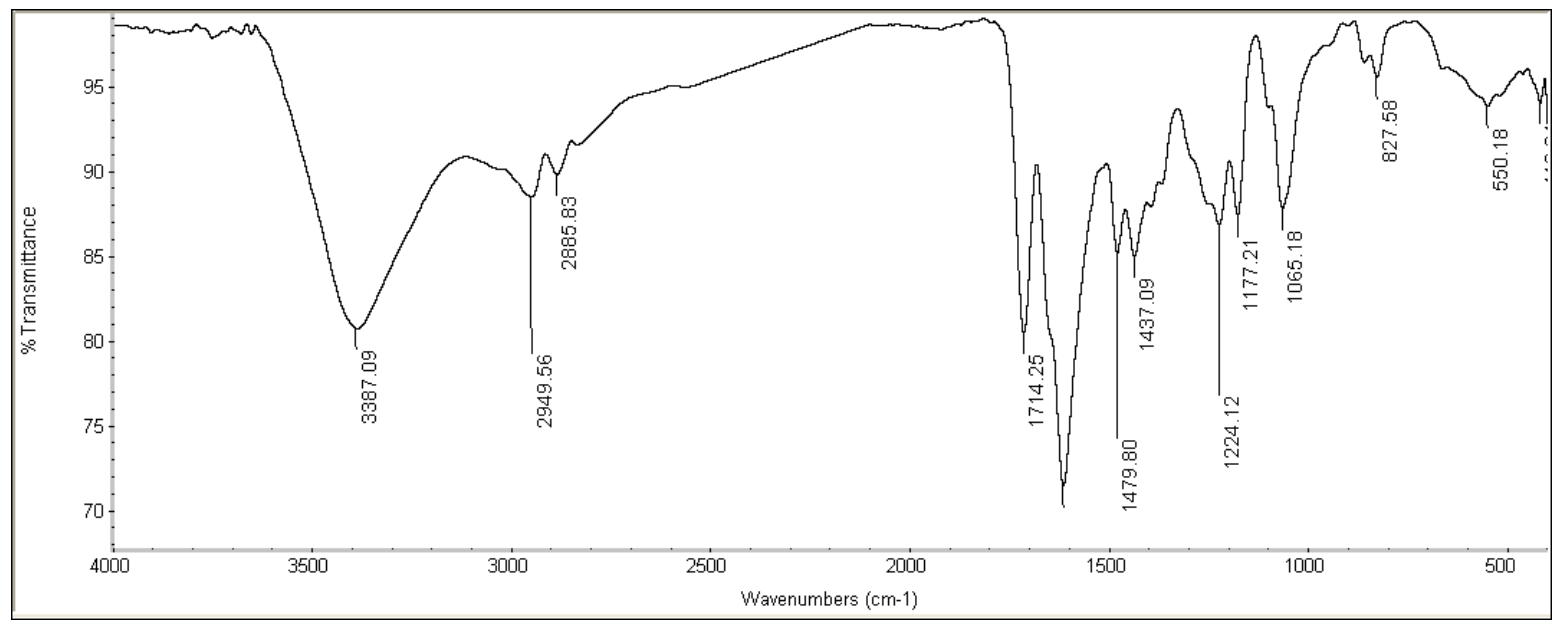

Fig. 1 FT-IR spectra of $\mathrm{AB}_{2}$ monomer 


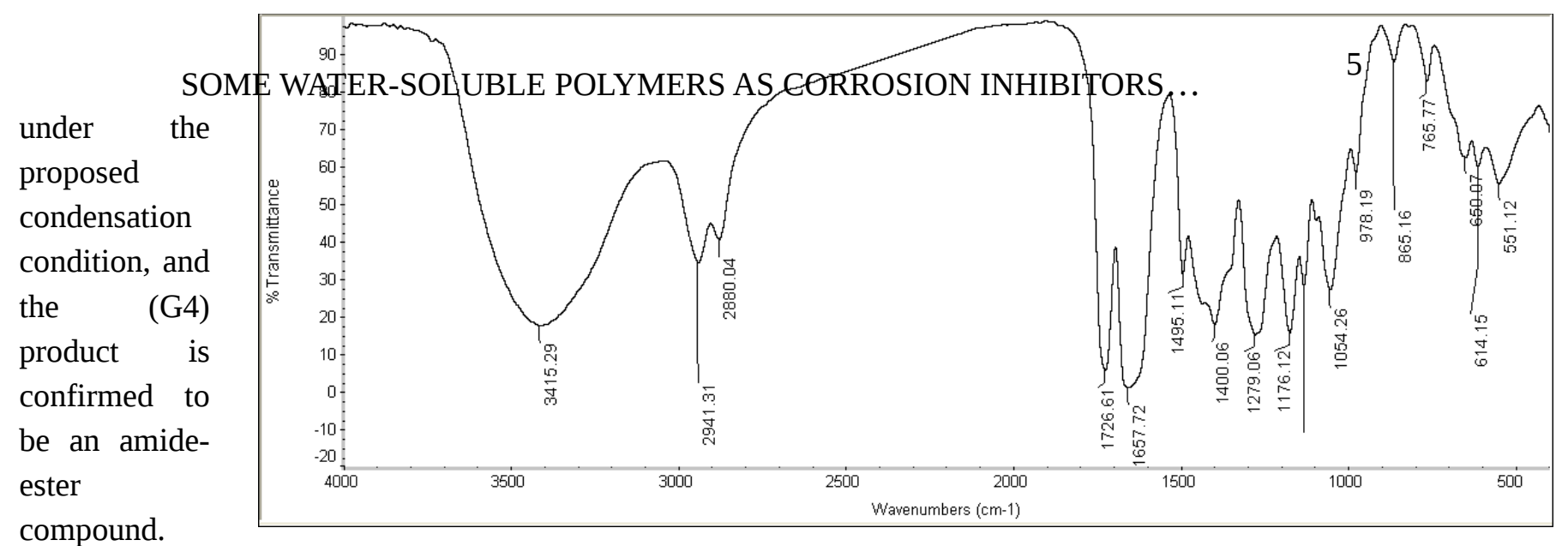

The

absorption

Fig. 2 FT-IR spectra of hyperbranched poly amide-ester generation 4 (G4)

band at $3415 \mathrm{~cm}^{-1}$ range is ascribable to the stretching vibration of hydroxyl group, showing that the hydroxyl groups of $\mathrm{AB}_{2}$ monomers have not completely reacted with the carboxyl groups on them or their oligomers. The results indicate that $\mathrm{AB}_{2}$ monomer can polycondense by self-catalysis [27], and trimethylol propane serving as a "center core" leads to few changes in the structures of hyperbranched macromolecules

\subsection{Study the protection efficiency of C-Steel electrode by the electrochemical technique}

\subsubsection{Potentiodynamic polarization}

The electrochemical polarization measurements of carbon steel in $1 \mathrm{M} \mathrm{HCl}$ without and with various concentrations $(50,100,200,400,500$ and 1000ppm) of HPAE generation 3 and 4 (G3 \& G4) are shown in Fig. 3. The values of electrochemical parameters such as corrosion potential $\left(\mathrm{E}_{\text {corr }}\right)$, cathodic and anodic Tafel slopes $\left(\beta_{\mathrm{a}}\right.$ and $\beta_{\mathrm{c}}$ ) and corrosion current density $\left(\mathrm{I}_{\text {corr }}\right)$ were extracted by Tafel extraploting the anodic and cathodic lines and are listed in Table 1 . The percentage of inhibition efficiency (IE \%) was calculated using the following equation [28]:

$$
\mathrm{IE} \%=\frac{\frac{\left(x_{0}-x_{1}\right.}{I_{0}}}{I_{0}} X 100
$$

where $I_{0}$ and $I$ are the corrosion current densities in the absence and presence of inhibitors respectively.

It was observed that the polarization resistance (Rp) and inhibition efficiency (IE\%) increase as the concentration of HPAE increase. The highest inhibition efficiency was obtained at $1000 \mathrm{ppm}$ concentration. This also indicates that more inhibitor particles were adsorbed on the surface of the metal thus providing a wider surface coverage and the extract acts as an adsorption inhibitor [29]. It can be observed from Table 1 that the corrosion current density ( $\mathrm{I}_{\text {corr }}$ ) decreases with increases in the concentration of HPAE which is due to the increase in the blocked fraction of the metal surface by adsorption [30]. The shift in the Tafel slopes of both the cathodic reaction $(\beta c)$ and anodic reaction $(\beta a)$ as shown in Fig. 3 in the presence and absence of HPAE suggest that the inhibitor affects both the cathodic and anodic reactions. This also suggests that HPAE is a mixed type of inhibitor. It can also be observed from Fig. 4 that as the concentration of the HPAE increases, there appears to be a shift towards more negative potential indicating that the HPAE acts as a good corrosion inhibitor. It can be observed that as the corrosion current density $\left(\mathrm{I}_{\text {corr }}\right)$ decreases, the inhibition efficiency (IE)\% increases as the concentration of the HPAE is increased. This suggests that the HPAE retards the reactions at both the cathodic and the anodic sites as a result of coverage of these sites by the molecules of the HPAE [31]. The shift in $\beta c$ and $\beta$ a values as shown in Table 1 indicates that 
KHALID I. KABEL, et al.

adsorption of HPAE modifies the mechanism of anodic dissolution and the cathodic hydrogen evolution, this reveals that the inhibition mechanism occurred by simply blocking the available cathodic and anodic sites of the metal surface [32]. The inhibition efficiency obtained from polarization measurements is found to follow the order: G4 > G3, indicating the more beneficial effect of compound G4 on corrosion inhibition of carbon steel.

\subsection{2. spectroscopic measurements (EIS)}

EIS measurements provide a better understanding of the corrosion mechanism taking place at the electrode surface including the kinetics of the electrode processes and simultaneously about the surface properties of the investigated systems. The method is widely used for investigation of the corrosion inhibition processes [33]. The Nyquist plots of carbon steel in $1 \mathrm{M} \mathrm{HCl}$ solution in the absence

Table 1. Electrochemical polarization parameters for the corrosion of carbon steel in $1 \mathrm{M} \mathrm{HCl}$ containing various concentrations of G3 and G4.

\begin{tabular}{|c|c|c|c|c|c|c|c|c|}
\hline Inhibitor & $\begin{array}{l}\text { Conc. } \\
\text { (ppm) }\end{array}$ & $\begin{array}{c}\mathrm{R}_{\mathrm{p}} \\
\left(\Omega \mathrm{cm}^{2}\right)\end{array}$ & $\begin{array}{l}E_{\text {corr }} . \\
\text { (mv) }\end{array}$ & $\begin{array}{c}\text { Icorr } \\
\left(\mathrm{mAcm}^{-2}\right)\end{array}$ & $\begin{array}{c}\beta_{\mathrm{a}} \\
\left(\mathrm{mv} \mathrm{dec}^{-1}\right)\end{array}$ & $\begin{array}{c}\beta_{c} \\
\left(\mathrm{mv} \mathrm{dec}^{-1}\right)\end{array}$ & IE\% & $\theta$ \\
\hline G3 & Blank & 69.09 & -522.6 & 1.0405 & 199.9 & -188.4 & - & - \\
\hline & 50 & 153.6 & -510.4 & 0.2394 & 144.9 & -127.9 & 76.99 & 0.769 \\
\hline & 100 & 166.62 & -499.6 & 0.1904 & 88.6 & -103.1 & 81.70 & 0.817 \\
\hline & 200 & 171.06 & -580.6 & 0.1772 & 118.4 & -110.0 & 82.96 & 0.829 \\
\hline & 400 & 346.91 & -523.1 & 0.1477 & 154.3 & -137.7 & 85.80 & 0.858 \\
\hline & 500 & 478.37 & -525.1 & 0.1203 & 151.0 & -144.6 & 88.43 & 0.884 \\
\hline & 1000 & 487.13 & -523.4 & 0.0998 & 129.2 & -137.5 & 90.40 & 0.904 \\
\hline \multirow{6}{*}{ G4 } & 50 & 240.50 & -525.1 & 0.1997 & 141.5 & -144.4 & 80.80 & 0.808 \\
\hline & 100 & 268.18 & -524.0 & 0.1756 & 126.6 & -140.6 & 83.12 & 0.831 \\
\hline & 200 & 344.83 & -526.7 & 0.1455 & 143.0 & -141.8 & 86.01 & 0.860 \\
\hline & 400 & 441.34 & -529.1 & 0.1257 & 144.5 & -141.5 & 87.91 & 0.879 \\
\hline & 500 & 398.39 & -536.8 & 0.1068 & 117.4 & -134.6 & 89.73 & 0.897 \\
\hline & 1000 & 611.03 & -540.7 & 0.0714 & 122.2 & -132.7 & 93.13 & 0.931 \\
\hline
\end{tabular}

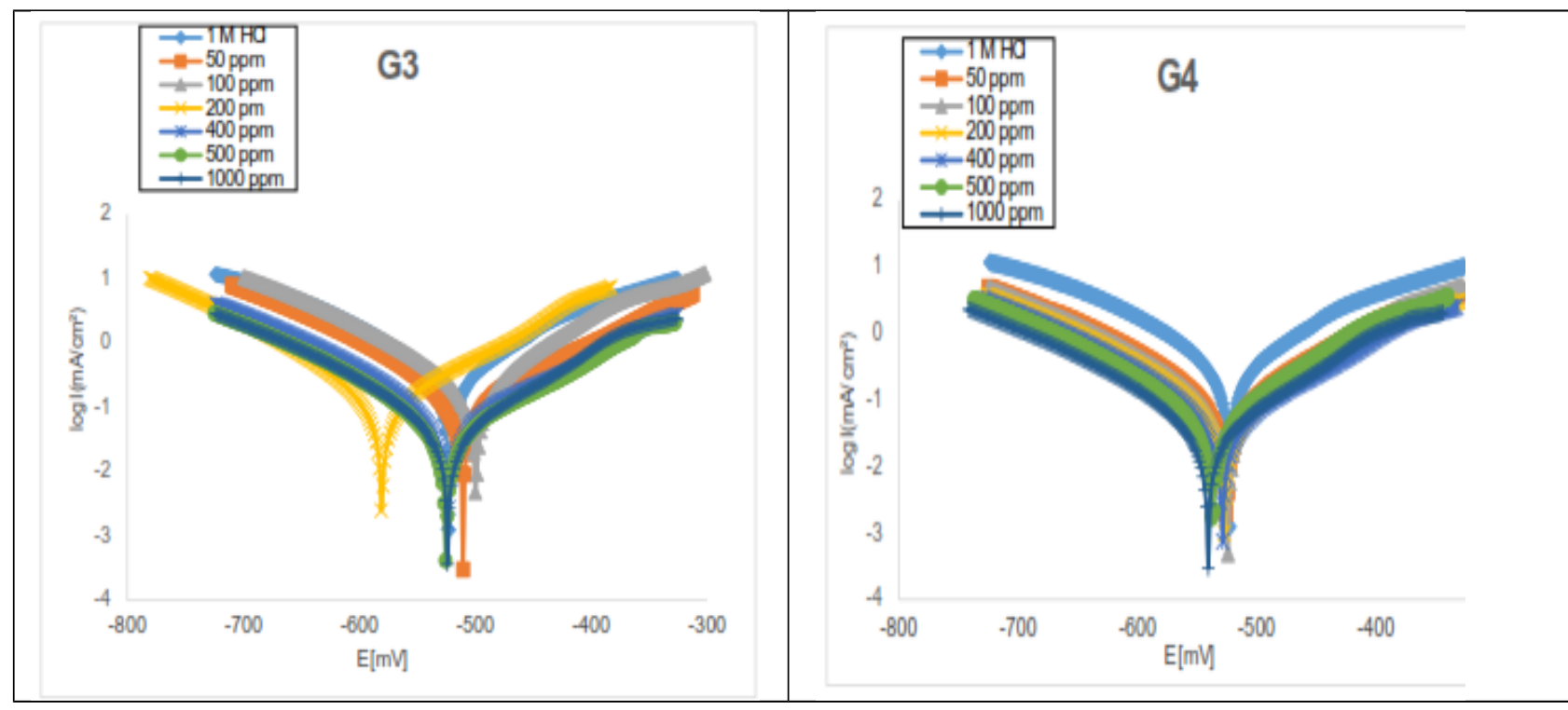

Fig. 3. Potentiodynamic polarization curves for carbon steel in $1 \mathrm{M} \mathrm{HCl}$ without and with various concentrations of G3 and G4. 
SOME WATER-SOLUBLE POLYMERS AS CORROSION INHIBITORS...

and presence of different concentrations of the synthesized inhibitors given in Fig. 4. It is clear from the figure that all impedance spectra have a depressed semicircular shape in the complex impedance plane, with the center under the real axis. Deviations from a perfectly circular shape indicate the frequency dispersion of the interfacial impedance [34].

The values of percentage inhibition efficiency were calculated from the values of charge transfer resistance $\left(\mathrm{R}_{\mathrm{ct}}\right)$ according to the following equation [35]:

$$
\mathrm{IE} \%=\frac{\text { Rct }-\mathrm{R}_{\mathrm{o}} \mathrm{ct}}{\text { Rct }} X 100
$$

where $R_{c t}$ and $R_{o c t}$ are the charge transfer resistances with and without the inhibitors, respectively. Inhibition efficiencies and other calculated impedance parameters obtained from fitted spectra are given in Table 2. As seen from Table 2 , the charge transfer resistance $\left(R_{c t}\right)$ values of inhibited substrates increase with the concentration of inhibitors. The most pronounced effect and the highest $R_{c t}$ are obtained by inhibitor (G4). A large Rct values are generally associated with a slower corroding system as the $\mathrm{R}_{\mathrm{ct}}$ value is a measure inversely proportional to the corrosion rate [36]. On the other hand, the values of $C_{d l}$ decrease with an increase in inhibitor concentration. This situation was the result of an increase in the surface coverage by these inhibitors which led to an increase in the inhibition efficiency. Also, this effect leads to a protective film, inhibiting species or both on carbon steel surface.

This decrease in the $\mathrm{C}_{\mathrm{dl}}$, which can result from a decrease in local dielectric constant and/or increase in thickness of the electrical double layer, suggested that the compounds act via adsorption at the metal/solution interface [37]. It could be assumed that the decrease of $\mathrm{C}_{\mathrm{dl}}$ values is caused by the gradual replacement of water molecules by adsorption of organic molecules on the electrode surface, which decreases the extent of the metal dissolution [38]. The adsorption can occur either directly on the basis of donor-acceptor interaction between the unshared electron pairs and/or pelectrons of inhibitor molecule and the vacant d-orbitals of the metal surface or by interaction of the inhibitors with already adsorbed chloride ions [39]. These results confirm that all of the synthesized inhibitors exhibit good inhibiting

Table 2. Electrochemical impedance parameters and inhibition efficiency for the corrosion of carbon steel in $1 \mathrm{M} \mathrm{HCl}$ containing various concentrations of G3 and G4.

\begin{tabular}{|c|c|c|c|c|c|}
\hline \multirow{3}{*}{ Inhibitor } & Conc.(ppm) & $\begin{array}{c}\text { Rs } \\
\text { ohm.cm }\end{array}$ & $\begin{array}{c}\text { Rct } \\
\text { ohm.cm }\end{array}$ & $\begin{array}{c}\mathrm{C}_{\mathrm{dl}} \\
\mathrm{FF} / \mathrm{cm}\end{array}$ & (\%) $\theta$ \\
\hline $\mathrm{G}_{3}$ & Blank & 3.299 & 60.92 & 653.0 & - \\
\hline \multirow{6}{*}{} & 50 & 3.732 & 247.5 & 179.9 & 75.38 \\
\cline { 2 - 6 } & 100 & 4.009 & 287.9 & 87.34 & 78.83 \\
\cline { 2 - 6 } & 200 & 5.704 & 333.6 & 84.90 & 81.73 \\
\cline { 2 - 6 } & 400 & 4.227 & 390.7 & 64.34 & 84.40 \\
\cline { 2 - 6 } & 500 & 4.443 & 467.3 & 51.02 & 86.96 \\
\hline \multirow{5}{*}{$\mathrm{G}_{4}$} & 1000 & 9.554 & 555.1 & 38.14 & 89.02 \\
\cline { 2 - 6 } & 50 & 6.011 & 311.2 & 64.68 & 80.42 \\
\cline { 2 - 6 } & 100 & 6.613 & 352.1 & 51.48 & 82.69 \\
\cline { 2 - 6 } & 200 & 7.473 & 389.4 & 51.13 & 84.35 \\
\cline { 2 - 6 } & 400 & 6.143 & 476.6 & 46.74 & 87.21 \\
\cline { 2 - 6 } & 500 & 10.21 & 558.6 & 45.19 & 89.09 \\
\hline
\end{tabular}


KHALID I. KABEL, et al.

and the more efficient to inhibit the corrosion of carbon steel is compound (G4). It is worth noting that the inhibition efficiencies calculated from EIS measurements are in good agreement with that obtained from potentiodynamic polarization measurements.

\subsection{Scanning Electron Microscopy (SEM)} Analysis.

In order to verify if the HBPA in fact adsorbed on the steel surface, SEM analysis was carried out. The SEM photograph for the polished steel surface before immersion in $1 \mathrm{M}$ $\mathrm{HCl}$ solution is shown in Fig. 5. The photograph shows the surface was smooth,clear and without pits. A photograph of the steel surface after immersion in $1 \mathrm{M} \mathrm{HCl}$ solution is shown in Fig. 6. The photograph revealed that, the surface was strongly damaged in the
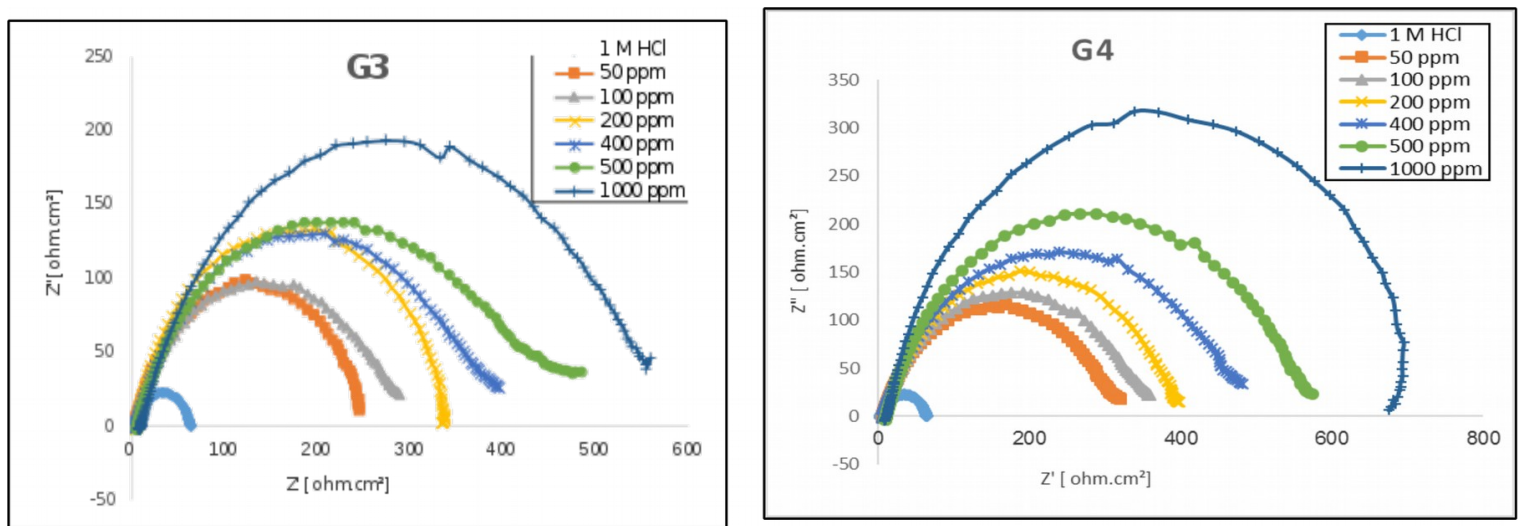

Fig. 4. Nyquist plots for carbon steel in $1 \mathrm{M} \mathrm{HCl}$ without and with various concentrations of G3 and G4.

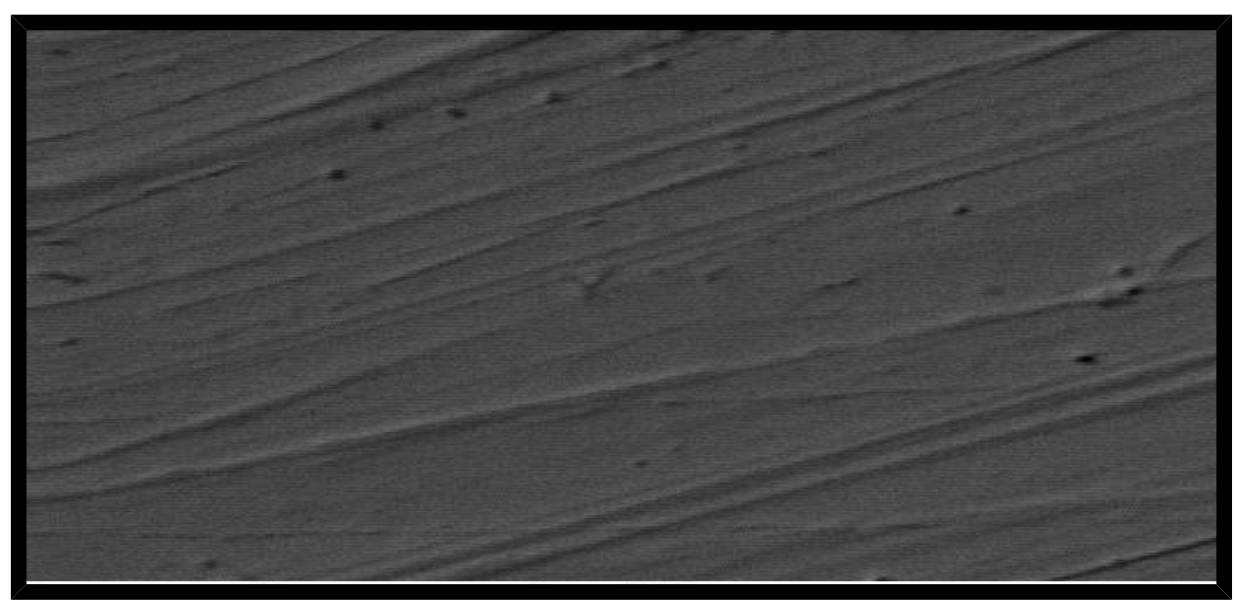

Fig. 5: SEM micrographs of steel surface before immersion in $1 \mathrm{M} \mathrm{HCl}$ absence of HBPA. A photograph of the steel surface after immersion in $1 \mathrm{M} \mathrm{HCl}$ solution containing 1000 ppm of HBPA is shown in Fig. 7. It was found that the faceting observed in figures disappeared and the surface was free from pits and it was smooth. It can be concluded from Figures (5-7) that corrosion decreased largely in the presence of HBPA hence corrosion was inhibited strongly when HBPA was present in the medium. In the presence of 1000 ppm of HBPA, there is much less damage on the steel surface, which further confirm the inhibit ion action. Also, there is an film adsorbed on mild steel surface.

In accordance, it might be concluded that the adsorption film can efficiently inhibits the corrosion of steel. 


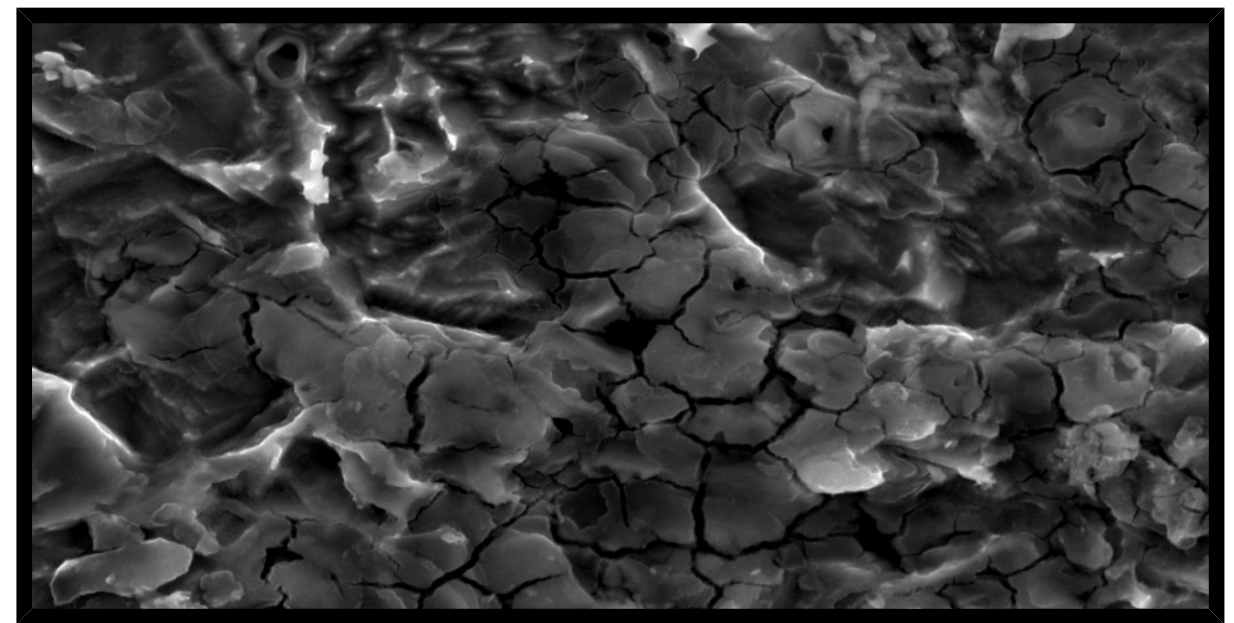

Fig. 6: SEM micrographs of steel surface after $12 \mathrm{hrs}$ of immersion in $1 \mathrm{M} \mathrm{HCl}$

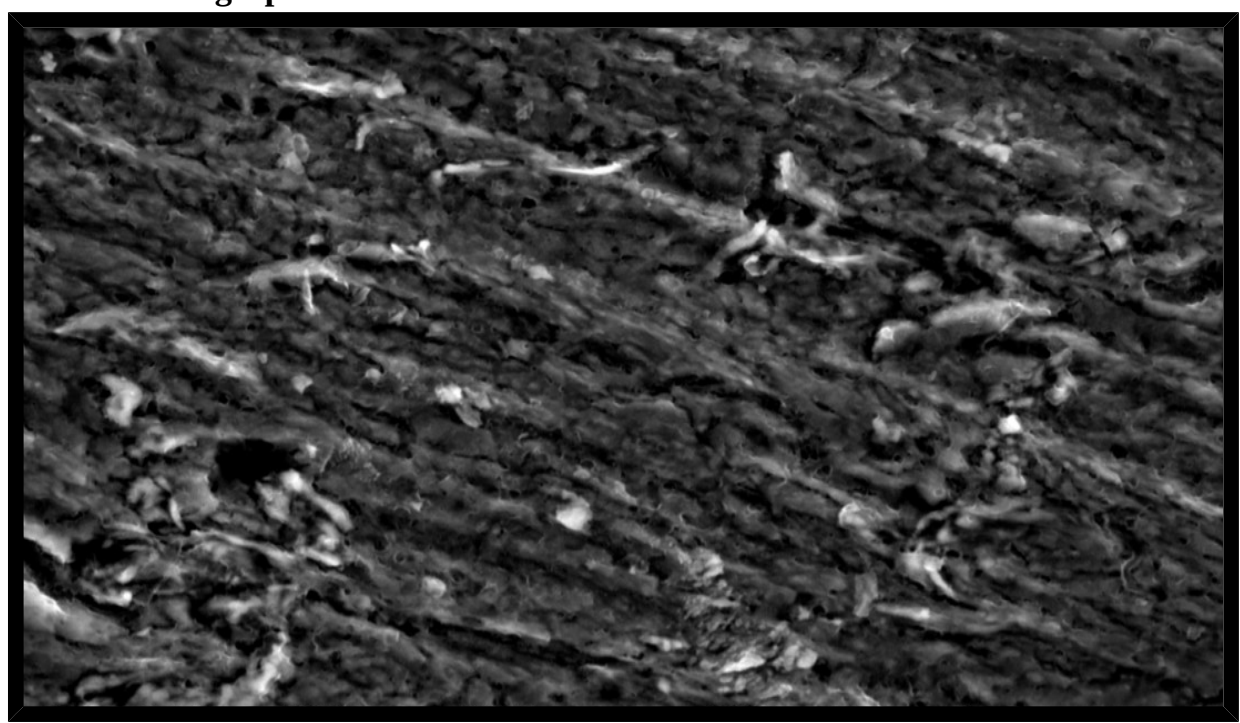

Fig. 7: SEM micrographs of steel surface after 12 hrs of immersion in $1 \mathrm{M} \mathrm{HCl}+1000 \mathrm{ppm}$ of G4 HBPA

\section{CONCLUSIONS}

(1) The results showed that inhibitors HPAE generation 3 and 4 (G3 \& G4) have excellent inhibition efficiency for the corrosion of carbon steel in $1 \mathrm{M} \mathrm{HCl}$. The inhibition efficiency increases in the following order G4 > G3.

(2) The potentiodynamic polarization curves indicated HPAE generation 3 and 4 (G3 \& G4) that act as a mixed-type of inhibitors by inhibiting both anodic metal dissolution and cathodic hydrogen evolution reactions.
(3) The impedance results indicate that the value of charge transfer resistance increased and double layer capacitance decreased. This result can be attributed to the increase of thickness of electrical double layer

(4) The results of different techniques (potentiodynamic polarization, (Tafel) and electrochemical impedance spectroscopy (EIS) showed a good agreement with each other. This agreement among the different independent techniques proves the validity of these results. 


\section{REFERENCES}

1. Q.Liu, Z.Y. Zhu , W.Ke, C.I.Han and C.L. Zeng, Corros. Nace. 57(2001) 730.

2. D.Collins, R.E.Weyers and I.L. Al-Qadi, Corros. Nace. 49 (1993) 74.

3. F.Eghbali, M.H.Moayed, A.Davoodi and N.Ebrahimi, Corros. Sci. 53 (2011) 513.

4. A.S Fouda and A.S Ellithy., Corros. Sci. 51 (2009) 868.

5. S. Andreani, M. Znini, J. Paolini, L. Majidi, B. Hammouti, J. Costa1 and A. Muselli1, J. Mater. Environ. Sci. 1 (2016) 187.

6. M.A. Quraishi, I. Ahamad, A.K. Singh, S. K. Shukla, B. Lal and V. Singh, Mater. Chem. Phys. 112 (2008) 1035.

7. S. K. Shukla and M.A. Quraishi, J. Appl. Electrochem. 39 (2009) 1517.

8. S.K. Shukla ,M.A. Quraishi and R. Prakash, Corros. Sci. 50 (2008) 2867.

9. S.A. Ali, M.T. Saeed and S.U. Rahman, Corros. Sci. 45 (2003) 253.

10. M. Pardave, M. Romero, H. Hernandez, M. Quijano, N. Likhanova, J. Uruchurtu and J. Garcia, Corros. Sci. 54 (2012) 231.

11. A. Chetouani, B. Hammouti, T. Benhadda and M. Daoudi, Appl. Surf. Sci. 249 (2005) 375.

12. S.Rajendran, S.P. Sridevi, N. Anthony, A. John and M. Sundearavadivelu, Anti-Corros. Methods Mater 2 (2005) 52(2) 102.

13. G.A. Bereket, A. Yurt and H.Turk, Anti-Corros. Methods Mater 6 (2003) 422.

14. M.Daouadji and N.Chelali, J Appl Polym Sci 90 (2004) 1275.

15. S.Selvaraji, A.Kennedy, A. Amalraj, S .Rajendran and N.Palaniswamy, Corros. Rev 22 (2004) 219.

16. R. Manickavasagam, K. Jeya, M. Paramasivam and S. Venkatakrishnalyer , AntiCorros. Methods Mater 49 (2002)19.

17. M. Morooka, I. Sekine, T. Tanaki, N. Hirosett and M.Yuasa , Corros. Eng 50 (2001) 106.

18. J. Jianguo, W. Lin, V. Alego and D.Schweinsberg, Corros. Sci 37 (1995) 975.

19. A.Dubey and G.Singh , Port Electrochim Acta 25 ( 2007) 221.

20. S.Umoren, E.Ebenso, P.Okafor and O.Ogbobe , Pigment Resin Technol 35(2006) 346.

21. Y. Wu, Journal of Applied Solution Chemistry and Modeling 2(2013) 33-46.
22. A. Labena, K.I. Kabel, R.K. Farag, Materials Science and Engineering 58 (2016) 1150-1159.

23. H. Bergenudda, P. Erikssona, C. DeArmittb, B. Stenberga and E.M. Jonssona, Polymer Degradation and Stability 76 (2002) 503-509.

24. G. A. El-Mahdy, A.M. Atta, H. A. Al-lohedan and A. O. Ezzat, Int. J. Electrochem. Sci., 9 (2014) 7925 - 7934.

25. Q.Chen, R.G.Chen, L.R.Xiao, Q.R.Qian and W. G. Zhang , 27 (2008) 877.

26. Y. Zheng, Y. G.Li, L.Pan and Y. S. Li, Polymer 48 (2007) 2496.

27. S. J. Wang, X. W. Ba, B. H. Zhao, S. W. Zhang and W. L.Hou, Acta Polym. Sin. (2004) 5, 634639.

28. S. Issaadi, T. Douadi, A. Zouaoui, S. Chafaa, M.A. Khan and G. Bouet, Corros. Sci. 53 (2011).

29. O.Mokhtari, I.Hamdani, A.Chetouani, A.Lahrach, H.El Halouani, A.Aouniti and M.Berrabah, Journal of Material Environmental Science, 5 (2013)310.

30. A.S Fouda, Y.Aggour, G.Bekheit and M.A. Ismail, International Journal of Advanced Research, 2 (2014)1158.

31. A. El-Shafei, S.A. Abd El-Maksoud and A.S. Fouda, Corrosion Science, 46 (2004).579.

32. A. Abdel-Gaber, B.A. Abd-El-Nabey and M.Saadawy, Corrosion Science, 51 (2009)1038.

33. N.A. Negm, N.G. Kandile, E.A. Badr and M.A. Mohammed, Corros. Sci. 65 (2012) 94.

34. J.C. da Rocha, J.A.C.P. Gomes, E. D’Elia, Corros. Sci. 52 (2010) 2341.

35. M. Moradi, J. Duan and X. Du, Corros. Sci. 69 (2013) 338.

36. A. Istiaque, P. Rajendra and M.A. Quraisi, Corros. Sci. 52 (4) (2010) 1472.

37. B. Qian, J. Wang, M. Zheng and B. Hou, Corros. Sci. 75 (2013) 184.

38. N.A. Negm, E.A. Badr, I.A. Aiad, M.F. Zaki and M.M. Said, Corros. Sci. 65 (2012) 77.

39. M. Behpour, S.M. Ghoreishi, N. Soltani, M. Salavati-Niasari, M. Hamadanian and A. Gandomi, Corros. Sci. 50 (2008) 2172. 
